\title{
Socioeconomic and Agroecological Determinants of Conserving Diversity On-farm: The Case of Rice Genetic Resources in Nepal
}

\author{
Devendra Gauchan ${ }^{1 *}$, Melinda Smale ${ }^{2}$, Nigel Maxted ${ }^{3}$, Mathew Cole ${ }^{4}$, Bhuwon R Sthapit ${ }^{5}$, Devra Jarvis ${ }^{5}$ \\ and Madhusudan P Upadhyay ${ }^{1}$ \\ ${ }^{1}$ Nepal Agricultural Research Council (NARC), PO Box 5459, Kathmandu-Nepal \\ ${ }^{2}$ International Food Policy Research Institute (IFPRI), Washington, USA \\ ${ }^{3}$ School of Biosciences, University of Birmingham, B15, 2TT, United Kingdom \\ ${ }^{4}$ Department of Economics, University of Birmingham, United Kingdom \\ ${ }^{5}$ International Plant Genetic Resource Institute (IPGRI), Rome, Italy
}

\begin{abstract}
Conservation of crop genetic resources presents a challenge of identifying specific determinants driving maintenance of diversity at farm and agroecosystems. The objectives of this study were to identify socioeconomic, market and agroecological determinants of farmers' maintenance of rice diversity at the household level and derive implications for policies in designing on-farm conservation programs. We assess spatial rice diversity at farm level using household survey data. A household decision making model is conceptualised using microeconomic theory to assess and identify factors influencing on-farm rice diversity. The model is then tested econometrically by using various factors affecting farmers' variety choice and diversity decisions. The findings show that household-specific socioeconomic, agroecological and market factors are important in determining on-farm rice diversity. The significant variables in explaining richness and evenness of rice diversity include distance to the nearest market, subsistence ratio, modern variety sold, land types and adult labour working in agriculture. The statistical signs of the factors determining rice diversity are consistent in explaining the richness, dominance and evenness among rice varieties. Finally, the study implies that the cost-effective means of promoting and sustaining on-farm conservation programmes is to target them in market isolated geographic locations of high crop diversity where farm households have more heterogeneity of agroecological conditions and more active family adult labour working on-farm.
\end{abstract}

Key words: Diversity indices, dominance, evenness, on-farm conservation, rice diversity, richness

\section{INTRODUCTION}

On-farm conservation is the outcome of farmers' decisions to select, modify and maintain diversity. It involves farmers' decisions to continue cultivating and managing landraces in the agro-ecosystems and communities where they have evolved (Bellon et al 1997). Farmers choose to conserve particular crop varieties by sowing the seed of the varieties they demand, selecting the seed and replanting. The choices they make today not only affect their welfare but that of future society. Various socioeconomic, market and agroecological factors are known to play important role in farmers' choices and management of crop genetic diversity at the farm, agroecosystems and community levels. Targeting on farm conservation efforts, therefore presents a challenge of identifying specific social, economic and agroecological determinants driving on-farm maintenance of diversity and minimizing the cost to farmers and to society of forgoing the opportunity to plant modern varieties.

The genetics and ecological literatures offer a range of sophisticated options particularly the use of diversity indices for calculating level of diversity (Magurran 1991). The objectives of the diversity 
indices are to determine which populations to target for conservation to maximize diversity or to model the services provided by diversity. Diversity could be measured spatially or in time (Duvik 1984). Temporal diversity (diversity in time) could be measured using indices such as the average age and weighted (by area) average age of varieties grown by farmers (Brennan and Byerlee 1991). Spatial diversity is calculated using cultivated area share indices of the different varieties of the farmers (Van Dusen and Taylor 2003, Smale et al 2003, Benin et al 2003, Gauchan 2004). This approximates a measure of the diversity of the planted landscape. Crop genetic resource conservationist and applied scientists have used these measures as strategies and decision tools to conserve genetic resources both in in situ and ex situ genebanks. One of the advantages of using such indices is that the data can be condensed into a scalar measure for use in an analytical application (Meng et al 1998). Richness, evenness and dominance are the popular measures of spatial diversity commonly applied in ecological, genetic and agronomic literatures of plant genetic resources conservation. The measurement of "richness" looks at the total number of variants or count of varieties. The varietal "evenness" is the equality in the distribution of the named varieties or area share planted to each of the varieties. "Dominance" is defined as the proportion of the sample occupied by the most abundant species or variety (Smale et al 2003).

In Nepalese context, we lack empirical socioeconomic studies that are useful for measuring on-farm crop diversity using such spatial diversity indices in order to design strategies for on-farm conservation programs. Through the use of several spatial diversity indices that represent different diversity concepts, this study aims to compare diversity trade-offs among conservation objectives, such as maintaining numbers of distinct farmer named variety types versus the evenness and dominance in the distribution of those types. Though the presence of genetic diversity among or within crop populations is not necessarily observable in physical characteristics of the plants growing in the field, this study defines crop diversity as the observable variation in a particular plant feature (phenotypic) or a set of features either within or distinct set of populations of the same species locally identified and recognised by the farmers or scientists. Employing regression models, it aims to test the significance of the various socioeconomic, farm-specific agroecological and market factors affecting farmer's management of spatial rice diversity at farm-household level.

The purpose of the research was to provide economic explanation of farmer decision-making in the choice and maintenance of rice genetic diversity and inform policy decisions by identifying appropriate economic policies to support on-farm conservation in Nepal. The specific objectives are to apply an analytical framework from microeconomic theory to (i) identify farm-specific agroecological and socioeconomic factors that significantly influence rice diversity maintained by farmers positively and negatively; (ii) analyse possible diversity trade-offs between different measures of spatial diversity and (iii) suggest ways for on-farm conservation for rice genetic resources.

\section{MATERIALS AND METHODS}

\section{Site selection and descriptions}

This research focuses on two of the three "ecosites" of the in situ agrobiodiversity conservation on-farm project (Sthapit et al 2000) where farmers grow both landraces and modern varieties. They are Kachorwa village in Bara district (Tarai) and Begnas village in Kaski (Hill) district representing two distinct agroecosystems (Table 1). Bara ecosite in Tarai has better access to market and technologies as compared to Hill agroecosystem in Kaski ecosite. Farmers grow rice crop in small family-based subsistence to semi-commercialised farms with sizes varying from less than 0.1 to 1.0 hectare and hence the marketed ratio is very small. Rice is cultivated in a variety of micro-agroecological niches (defined here as "land types"), with lowland, mid-land, upland and swampy environments (Pokhari) often found 
within the same farm (Table 1). These rice land types are classified and recognised by farmers depending on the surface hydrology (moisture availability), topography and soil types (Gauchan 2000). Farmers often plant several local cultivars to match a range of land types, soils, moisture conditions and cropping sequences.

Table 1. Landraces cultivated in micro-ecological niches in two agroecosystems

\begin{tabular}{|c|c|c|c|}
\hline Agroecosystem & $\begin{array}{l}\text { Land types (micro-ecological } \\
\text { niche) }\end{array}$ & $\begin{array}{l}\text { Local name for land } \\
\text { types }\end{array}$ & Local name of adapted landrace \\
\hline \multirow[t]{4}{*}{ Tarai (Bara) } & Upper wet land & Uchha khet & Mutmur \\
\hline & Mid-wet land & Samtal khet & Mansara \\
\hline & Lower wet land & Nicha khet & Basmati \\
\hline & Deep water & Ghol khet & Bhathi \\
\hline \multirow[t]{5}{*}{ Hill (Kaski) } & Lower river basin & Sinchit khet/Phant & Jetho budho, Anadi \\
\hline & Hillside rainfed terrace & Tari khet & KatheGurdi, Mansara \\
\hline & Seasonal stream irrigated terrace & Kulo khet & Ekle \\
\hline & Swampy land & Dhab khet & Anadi, Jarneli Dhave \\
\hline & Unbunded terrace (upland) & Ghaiya bari & $\begin{array}{l}\text { Set Ghaiya, Rato Ghaiya, } \\
\text { Kunchhale Ghaiya }\end{array}$ \\
\hline
\end{tabular}

\section{Sample survey}

A survey of farming households was carried out employing random sampling framework in Tarai (Bara) and Hill (Kaski) ecosites by listing actual farming households from the available records in the local administrative offices (village development council and municipality). A random sample of 307 households (148 in Bara, 159 in Kaski) representing about 17\% of actively farming households was drawn using list census frame from a total list of 1785 households, with 860 households in Bara and 915 in Kaski. The survey instrument was a structured household questionnaire administered in personal interviews. Survey questions covered social, demographic, and economic characteristics of the farm households, as well as physical characteristics of their farms, economic aspects of rice production and market access. Both men and women farmers that are involved in rice production and consumption decisions were interviewed. Households were revisited immediately for missing information and inappropriate responses during the survey period. Peer review of the questionnaires was undertaken in regular intervals to check for measurement errors, ambiguities and missing information. Descriptive statistical analysis was carried out in SPSS package, whilst econometric analysis of the survey data was accomplished in LIMDEP econometric package (Greene 1998), designed specifically for models with discrete and limited dependent variables.

\section{Farm household model}

The genetic diversity in crops that are grown in farmers' fields is the outcome of farmers' allocation of crop area among several varieties. The conceptual approach of the model presented here is based on the theory of the agricultural household models (Singh et al 1986), as applied to variety choice and analysis of crop biodiversity by Van Dusen and Taylor (2003). Other related models and applications include Brush et al (1992), Meng (1997), Smale et al (2001) and Benin et al (2003). The reduced form equations given below express optimal area allocations $(\alpha)$ among crops and varieties as functions of a vector of prices $(p)$ (including wage), farm size $(A)$, exogenous income $(Y)$, and vectors of farm household socioeconomic $\left(\Omega_{H H}\right)$, farm physical $\left(\Omega_{F}\right)$ and market characteristics $\left(\Omega_{M}\right.$ :). Diversity $(D)$ on household farms is an outcome of the choices made in a constrained optimisation problem rather than an explicit choice. Equations estimated econometrically take the following conceptual form of the model, as in Van Dusen and Taylor (2003).

$$
D=D\left(\alpha^{*}\left(p, A^{0}, Y^{0}, \Omega_{H H}, \Omega_{F}, \Omega_{M}\right)\right)
$$




\section{Regression models and specifications}

The reduced form of the household model presented above in equation (i) is the conceptual basis for econometric analysis and hypothesis testing. Significance of the various household-specific socioeconomic, agroecological and market factors affecting farmers variety choice and diversity decisions are tested by specifying regressions with diversity indices as the dependent variables. Two sets of regressions, Poisson and Tobit regression models were used as outlined below.

Poisson regression model: The preponderance of small values and the clearly discrete nature of the dependent variable (variety count data) with non-negative integer suggest the use of a Poisson maximum likelihood regression (Greene 2000). The log-linear regression in the Poisson model naturally accounts for the non-negativity of the Poisson distribution dependent variable (Winkelmann and Zimmermann 1995). The count data specification for richness measure was utilised because of the way it gives the model flexibility to explain cultivar diversity within a crop. The Poisson regression model is given as:

$$
D_{i}=\beta_{o}+\beta_{1} X_{H}+\beta_{2} X_{F}+\beta_{3} X_{M}+\mathbf{e}
$$

Where, $\quad D_{i}=$ Measure of rice diversity-richness (count of rice varieties) of household $i$,

$\mathrm{X}_{\mathrm{H}}=$ Socioeconomic characteristics (age of production decision maker, education of production decision maker, percent female working adult, adult labour in agriculture, livestock assets, exogenous income, subsistence ratio)

$\mathrm{X}_{\mathrm{F}}=$ Agroecological characteristics (number of land types, percent rice area irrigated, plot dispersion)

$\mathrm{X}_{\mathrm{M}}=$ Market characteristics (total distance to market, landraces sold, MV sold)

$\mathrm{e}=$ Disturbance term

Tobit regression model: For modelling values of Shannon and Berger-Parker indices as the measure of evenness and inverse dominance respectively, Tobit model appears to be appropriate since some households had censored values with Shannon evenness index taking a value of 0 in some cases and the Berger-Parker index assuming a value of 1 , both values being the lower limits. According to Ammemiya (1974), censoring takes place when the dependent variable takes a limiting value. A reduced form equation is used in this paper to shed light on the underlying factors influencing households to maintain diversity $\left(\mathrm{D}_{\mathrm{i}}\right)$ in terms of evenness and inverse dominance indices of rice varieties. The general formulation for Tobit specification is usually given in terms of index function (Greene 2000),

$$
\begin{aligned}
& D_{i}^{*}=\beta^{\prime} X+\varepsilon_{i} \\
& D_{i}=0 \text { if } D_{i}^{*} \leq 0, \\
& D_{i}=D_{i}^{*} \text { if } D_{i}^{*}>0 .
\end{aligned}
$$

Where, $D_{i}{ }^{*}$ is a censored variable of the diversity indices. $\beta^{\prime}$ is a vector of parameters to be estimated and $\mathrm{X}$ is a vector of explanatory variables which includes household socioeconomic variables (age, education of decision makers, adult family labour working in agriculture, percent female adult, subsistence ratio, livestock assets), market variables (market distance, landraces sold, modern variety sold) and farm agroecological variables (number of land types, percent irrigated area, plot dispersions). $\varepsilon$ is the disturbance term.

Dependent variables: The dependent variables for the regression tests are household level diversity indices (Table 2) based on variety area shares and farmer named varieties (count). This study uses a 
simple count of farmer cultivated rice varieties as a measure of richness. Though in principle standardising by area (as in the Margalef index) may be preferred to a simple count; the small rice areas farmed in Nepal led to use of simple count as a measure of richness. Shannon index captures a combination of richness and equality or evenness in distribution across areas and it is also recently being used in economics research as measure of evenness for diversity measurement (see Van Dusen 2000, Benin et al 2003). The Berger-Parker index is employed to represent the relative dominance of one variety versus another. It is defined as the inverse of the proportion of the sample occupied by the most abundant species or variety (Smale et al 2003). Therefore, an increase in its value accompanies an increase in diversity and reduction in dominance.

Table 2. Definition of dependent variables for Poisson and Tobit regression models

\begin{tabular}{lllll}
\hline Index & Concept & Construction $\dagger$ & Explanation & Model \\
\hline Count & Richness & $\mathrm{D}=\mathrm{S}$ & $\begin{array}{l}\mathrm{S}=\text { number of rice } \\
\text { varieties }\end{array}$ & Poisson \\
Shannon & $\begin{array}{l}\text { Evenness (richness and } \\
\text { relative abundance) }\end{array}$ & $\mathrm{D}_{\mathrm{sh}}=-?_{\mathrm{i}} \alpha_{\mathrm{i}} \ln \alpha_{\mathrm{i}}$ & $\begin{array}{l}\alpha_{\mathrm{i}}=\text { variety area share }, \\
\mathrm{i}=1, \ldots \mathrm{S}\end{array}$ & Tobit \\
Berger-Parker & $\begin{array}{l}\text { Inverse dominance } \\
\text { (relative abundance) }\end{array}$ & $\mathrm{D}_{\mathrm{bp}}=1 / \mathrm{Max}\left(\alpha_{\mathrm{i}}\right)$ & $\begin{array}{l}\text { Where } \alpha_{\mathrm{i}}=\text { variety area } \\
\text { share, } \mathrm{i}=1, \ldots \mathrm{S}\end{array}$ & Tobit \\
\hline
\end{tabular}

†, D=Diversity index. Construction adapted from Magurran (1991). When one variety is grown, the lower limit of the Shannon index is zero and count and Berger-Parker indices are equal to one.

Explanatory variables and hypothesised effects: Explanatory variables and their hypothesised effects are shown in Table 3. These explanatory variables are grouped into household, farm-physical (agroecological) and market characteristics, as in the farm household decision-making model presented in equation (i). Household characteristics affect crop diversity both through preferences and the household-specific costs of market transaction, as well as through labour stocks and opportunity costs. Age, education and the gender composition of households affect diversity through their effect on preferences for consumption and production and experience level of cultivation. Subsistence ratio, exogenous income and livestock assets are all wealth-related variables and they affect diversity through their association with larger farm sizes and ability to bear risk.

Table 3 Definitions of explanatory variables and hypothesised effects on diversity

\begin{tabular}{|c|c|c|}
\hline Variable name & Variable definition & $\begin{array}{l}\text { Hypothesised } \\
\text { effect }\end{array}$ \\
\hline \multicolumn{3}{|c|}{ Household characteristic } \\
\hline Age & Age of the production decision-maker (years) & $(+)$ \\
\hline Education & Education of the production decision-maker (years) & $(+,-)$ \\
\hline Adult labour & Active family adult labour working on-farm (number) & $(+)$ \\
\hline Female adult & Per cent female of actively-working adults & $(+)$ \\
\hline Livestock assets & Value (NRs) of large animals (bullocks, dairy animals) & $(+)$ \\
\hline External income & $\begin{array}{l}\text { Average monthly household expenditure (NRs) since last harvest preceding } \\
\text { this season (exogenous income) }\end{array}$ & $(+,-)$ \\
\hline Subsistence ratio & Ratio of 5-year average of rice produced to rice consumed $(\mathrm{kg})$ & $(+,-)$ \\
\hline \multicolumn{3}{|c|}{ Farm-physical characteristic (agroecological) } \\
\hline Irrigation & Per cent rice area irrigated or with source of water & $(+,-)$ \\
\hline Land types & Number of rice land types (lowland, mid-land, upland) & $(+)$ \\
\hline Plot dispersion & $\begin{array}{l}\text { Total walking distances (minutes) from the house to the rice plot(s), divided by } \\
\text { cultivated hectares }\end{array}$ & $(+)$ \\
\hline \multicolumn{3}{|c|}{ Market characteristic } \\
\hline Market distance & Total walking distance from the house to the local market (minutes) & $(+)$ \\
\hline Landrace sold & Landrace grain sold by household in preceding season (KGs) & $(+)$ \\
\hline MV sold & Grain of modern variety sold by household in the preceding season (KGs) & $(-)$ \\
\hline
\end{tabular}

All prices and values are in Nepali Rupees (NRs). 
Relevant physical farm or agroecological characteristics include farm fragmentation and land heterogeneity measured by the number of land types, distances among rice plots, and the percent of rice area irrigated (or assured source of water). The more heterogeneous the conditions in which farmers cultivate the crop, the higher the expected level of diversity since such heterogeneity leads farmers to choose a broader set of varieties to suit multiple classes of farm land and seasonal niches.

Market variables affect diversity through the extent to which households trade their rice crop and purchase inputs, foods and other household needs in the market. The distance of the market from the homestead and farm plot is a major component of the cost of engaging in market transactions. The more removed a household is from a local market centre, the more likely that it would rely on its own production to meet its consumption needs. Past sales of grain of landraces are expected to relate positively to provide incentives for cultivating them. Past grain sales from production of modern varieties may relate to specialisation in fewer varieties. Market prices are not included here because they are fixed for all households in each ecosite and because rice markets are incomplete, the shadow prices govern farm households' decisions.

Tests of hypothesis: The null hypothesis that parameters are equal between the Bara (Tarai) and Kaski (Hill) ecosites $\left(\mathrm{Ho}=\mathrm{B}_{\mathrm{b}}=\mathrm{B}_{\mathrm{k}}\right.$ ) was rejected with a log-likelihood ratio test (Greene 2000: pp 152-153). This test result confirms the statistical significance of ecosite-specific factors both in terms of levels of diversity and the marginal effects of explanatory factors on these levels. The likelihood ratio $(\lambda)$ test is carried out by comparing the values of the log-likelihood function with and without the restrictions imposed. A separability test of the model was carried out to investigate whether the model used in this study is separable or not, with a joint test of the significance of the group of variables. The test of the hypothesis for separability was: $\mathrm{H}_{\mathrm{O}}=\beta_{\mathrm{HH}}=0, \beta_{\mathrm{M}}=0$. The significance of likelihood ratio $(\lambda)$ test for a group of variables (eg household, market) with and without restriction imposed led us to conclude that model is non-separable. This indicates that there is simultaneity in production and consumption decisions of rice farmers in the study sites and household and market factors do influence farmers' optimal varietal choices and diversity outcome.

\section{RESULTS AND DISCUSSION}

\section{Cultivation pattern and rice diversity}

Sample farmers in the study agroecosystems maintain a total of 50 and 23 rice cultivars in the hill and lowland agroecosystems, respectively (Table 4). Farmers cultivate both the highest number of total rice varieties (local and improved) $(n=50)$ and rice landraces $(n=39)$ in the hill agroecosystem. At the household level, farmers also cultivate higher mean number of total varieties and landraces and allocate larger area for landraces in hill agroecosystem. Though both modern varieties and landraces coexist in both agroecosystems, higher number of modern varieties and larger mean area on modern varieties are cultivated in lowland in Bara (Kachorwa). Variety area share index as estimated from Shannon index is also higher in hill agroecosystem (Kaski) indicating that farmers are maintaining higher level of rice diversity at the household level.

\section{Regression results}

The results (marginal effects) of Poisson and Tobit regression models for factors explaining variation in the richness, evenness and dominance among rice varieties grown by farm households in the study ecosites (Bara and Kaski) are presented in Table 5. The age and education of decision-makers are significant factors explaining rice diversity in Tarai (Bara) but not in the Hill (Kaski). Significance of age variable in Terai indicates that older farmers are more likely to allocate rice area more equally 
among varieties, perhaps due to their experience and because they are not as receptive to adopting and specialising in a single modern variety. Higher education levels among production decision-makers (usually men) in Bara are positively related to both evenness and inverse dominance. This indicates that education may expand the variety choice options for the rice farmers. More active household labour in agriculture generally contributes positively to rice diversity, and the marginal effects are particularly large in Hill (Kaski) where there are fewer non-farm employment opportunities and rice production requires more labour time. However, insignificance of female adult labour variable indicates that the gender composition of adult agriculture labour is of no apparent importance.

Table 4. Rice varietal diversity maintained at ecosite and farm household level

\begin{tabular}{lrrr}
\hline Cultivation pattern and rice diversity & \multicolumn{3}{c}{ Agroecosystems } \\
\cline { 2 - 4 } & Tarai (Bara) & Hill (Kaski) & All \\
\hline Ecosite level diversity & & & \\
Total number of cultivars & 23 & 50 & 77 \\
Total number of landraces & 5 & 39 & 44 \\
Total number of modern varieties (MVs) & 18 & 11 & 29 \\
Household level diversity & & & \\
No of rice growing households & 148 & 159 & 307 \\
Mean number of varieties grown & $2.11^{*}$ & 3.53 & 2.85 \\
Mean number of landraces grown & $0.118^{*}$ & 2.71 & 1.55 \\
Mean number of modern varieties grown & $1.98^{*}$ & 0.73 & 1.33 \\
Mean percent area planted in landraces & $3^{*}$ & 74 & 61 \\
Mean percent area planted in MVs & $97^{*}$ & 26 & 39 \\
Variety area share index (Shannon) & $0.54^{*}$ & 0.82 & 0.68 \\
\hline
\end{tabular}

* Pair wise t tests show significant difference of means between agroecosystems at $5 \%$, level with one-tailed test. Source: Gauchan (2004).

Irrigation (water availability) has positive effect on the maintenance of evenness of rice varieties in Tarai (Bara) but it has no effect in Hill (Kaski). As expected, distance from market centres is positively related to rice diversity. The further the distance of farm plots and households from markets, the higher the likelihood of maintaining evenness diversity. In Kaski, varietal richness and in Bara inverse dominance diversity was also positively related with market distance. While sales of the grain of landraces is of no importance, sales of the grain of modern varieties is associated with less evenly distributed varieties in either site and in Bara ecosite, with greater dominance by any single or few varieties. The more heterogeneous agroecological conditions (measured by number of land types and plot dispersion) in which the farmers cultivate the crop, the greater the numbers of rice varieties grown and the greater is the evenness in their area distribution in Kaski. Rice plots are more widely dispersed per unit area in Hill (Kaski) compared to Tarai (Bara), and within the Kaski ecosite, their dispersion is positively related to the richness, inverse dominance and equality among rice varieties on farms.

Similarly, surplus production (subsistence ratio) and market distance are positively related to the inverse dominance measure of diversity in Bara, whilst active adult agricultural (farm) labour, livestock assets and dispersion of plots are related to inverse dominance measure in Kaski. In Kaski (Hill), livestock assets contribute to less dominance by a single rice variety. Though outside sources of cash income are not significantly related to the diversity of rice varieties grown in these sites, surplus households also grow more varieties that are more evenly distributed. Higher sales of grains of modern varieties reduce evenness measures of diversity. 
Table 5. Factors explaining variation in the diversity of rice varieties grown by farmers in two ecosites (marginal effects of Poisson and Tobit regression models) $\dagger$

\begin{tabular}{lllllll}
\hline & \multicolumn{2}{c}{ Tarai (Bara) ecosite $(\mathrm{N}=148)$} & \multicolumn{2}{c}{ Hill (Kaski) ecosite $(\mathrm{N}=159)$} \\
\hline Variables & Richness & Evenness & $\begin{array}{l}\text { Inverse } \\
\text { dominance }\end{array}$ & Richness & Evenness & $\begin{array}{l}\text { Inverse } \\
\text { dominance }\end{array}$ \\
\hline Constant & -0.5533 & $-0.816^{* * *}$ & 0.3927 & 0.1917 & -0.2253 & 0.6457 \\
Age & 0.0038 & $0.0052^{* *}$ & 0.0064 & -0.0068 & -0.00157 & -0.0061 \\
Education & 0.0405 & $0.0193 *$ & $0.0331 *$ & 0.0243 & 0.00076 & -0.0087 \\
Female adult & -0.6165 & -0.2571 & -0.4569 & -0.5358 & -0.07935 & -0.6042 \\
Adult labour & 0.1896 & $0.0781 * * *$ & 0.0214 & $0.4853 * * *$ & $0.14407 * * *$ & $0.1243 *$ \\
Livestock assets & 0.000007 & 0.000005 & 0.000004 & 0.00001 & 0.000005 & $0.00002 *$ \\
External income & 0.00003 & 0.00002 & 0.00008 & 0.00004 & -0.000003 & -0.000008 \\
Subsistence ratio & 0.2940 & $0.2163 * * *$ & $0.2584 *$ & $1.2590 *$ & $0.31802 * *$ & 0.4851 \\
Irrigation & 0.2537 & $0.1203 *$ & $0.2436 * *$ & 0.4486 & 0.04772 & -0.1327 \\
Land types & $0.4198 *$ & $0.1937 * * *$ & 0.1233 & 0.4138 & $0.1141 *$ & -0.1292 \\
Plot dispersion & -0.0003 & -0.0002 & -0.0003 & $0.0026 * *$ & $0.00072 * * *$ & $0.00151 * *$ \\
Market distance & 0.0012 & $0.0009 * * *$ & $0.0012 * * *$ & $0.0013 * * *$ & $0.00027 * *$ & 0.0003 \\
Landrace sold & -0.0002 & -0.0002 & -0.0003 & -0.00061 & 0.00002 & -0.0002 \\
MV sold & -0.00005 & $-0.00009 *$ & $-0.00014 *$ & -0.00057 & $-0.0003 *$ & -0.0006 \\
Log likelihood function & -204.6 & -78.63 & -157.15 & -263.34 & -85.72 & -250.75 \\
\hline
\end{tabular}

$\dagger$, Regression model for richness is Poisson; for evenness Tobit censored at zero; and for inverse dominance Tobit censored at one. One tailed Z-tests significant at $P<0.01(* * *), 0.05$ (**), 0.1 (*) percent level. Z-statistic is relevant for maximum likelihood estimation. Marginal effects are computed at the means of explanatory variables.

Though genetic studies (molecular and agromorphological) of landraces grown by the farmers as reported by Bajracharya (2003) has revealed that both Kaski and Bara ecosites grow more genetically diverse landraces based on selected genetic analysis of sample of landraces, this economic study has shown that farmers in Kaski ecosite as compared to Bara are more likely to maintain and sustain diversity given the economic opportunity they face. Diversity indices presented in this study also serve as proxies for public values for the set of crop populations. No trade-offs appear to be associated with public investments that promote richness, evenness or equality in the distribution of rice varieties on farms in either ecosite. The direction of a statistically significant effect is the same across diversity concepts, though there was some difference in the magnitude of the effects and significance of the factors in each ecosite. This result appears to be similar to the findings of Benin et al (2003) for cereal diversity in Ethiopia. The agroecological heterogeneity (farm-physical) and market distance which have been found to play important roles in the maintenance of rice diversity in this study are supported by the earlier works of Meng (1997) for wheat landrace diversity in Turkey and Van Dusen (2000) from Milpa cultivation and diversity in Mexico. The fact that households with an active family labour on-farm have greater crop diversity is also supported by previous research. Benin et al (2003) studied the diversity of cereal crops in Ethiopian highlands and found that maize diversity is related to availability of larger stocks of family labour.

Different socioeconomic, market and agroecological factors are significant in explaining the richness and evenness among rice varieties grown in both Tarai (Bara) and hills (Kaski) but they are consistent in sign. Farmers' choices and cultivation of rice varietal diversity and their possible implications on conservation policy are indicated by the significance of marginal probabilities of the explanatory variables. These significance variables are farm adult labour, subsistence ratio, market distance and land types in both of the ecosites. No diversity trade-offs are observed with public investment policy promoting different measures of diversity such as richness versus evenness. This indicates that a program designed to conserve the richness of varieties of rice crop is not likely to have a negative 
impact on the evenness among them. Thus, a policy whose goal is to augment one conservation goal would not conflict with another.

Regression results (marginal probabilities) suggest that Kaski (Hill) ecosite has higher marginal probabilities for many of variables that have shown positive significance for on-farm diversity. This finding also shows that on-farm conservation programs need to be targeted in market isolated locations with high farm agroecological heterogeneity since, in such locations, it will be cost-effective to intervene and more likely to be sustained for longer term provided these locations harbour genetic resources that are of high conservation interest. The study also infers that policies that affect the supply of adult household farm labour working in agriculture are likely to have a major impact on the varietal diversity. If the opportunities for non-farm employment increase and fixed adult agricultural labour stocks are drawn out of farm production, it may have a negative impact on prospects for on-farm conservation. However, the feasibility and costs of implementing such a program would require further investigation. Clearly, ricegrowing household in the hill (Kaski) ecosite with better possession of farm labour, land and livestock assets and those cultivating diverse land types and more dispersed plots that are located farther away from market centres are more likely to maintain richness and evenness measures of diversity.

Indices of genetic diversity employed here are based on area shares and variety counts. Better results on diversity may be obtained by combining household socio-economic information with an accurately measured genetic data at the molecular level that may probably shed more light on where the most diverse genetic resources are found within the study locations, communities and specific group of households (poor or rich). As constructed, the diversity indices treat all material as equally important for conservation. That is, these goals are related to the numbers, evenness or equitability of varieties grown in communities without regard to the nature of the varieties or the social value of the diversity conserved. A study that links with social valuation and that covers households located across a large range of diverse communities and locations will provide better pictures of cultivation of socially valued landraces and capture dynamics of wider variations of locations and communities.

\section{ACKNOWLEDGMENTS}

This paper is based on research conducted as part of the in situ conservation of agrobiodiversity on-farm project Nepal (NARC/LIBIRD/IPGRI). We are grateful to members of in Situ project team, Nepal, particularly, the field staff in Bara and Kaski ecosites for their support in the field survey. The authors are also thankful to senior scientists T Hodgkin and P Eyzaguirre (International Plant Genetic Resources Institute) for their insights and for the contributions of E Van Dusen, University of California, Berkeley. This research was supported by the International Development Research Centre of Canada (IDRC) and the European Union.

\section{REFERENCES}

Amemiya T. 1974. Multivariate regression and simultaneous equation models when the dependent variables are truncated normal. Econometrica 42:999-1012

Bajracharya J. 2003. Genetic diversity study in landraces of rice (Oryza sativa L) by agro-morphological characters and microsatellite DNA markers. PhD thesis. School of Agricultural and Forest Sciences, University of Wales, Bangor.

Bellon MR, JL Pham and MT, Jackson.1997. Genetic conservation: A role of rice farmers. In: Plant genetic conservation: The in situ approach (N Maxted, BV Ford-Lloyd and JG Hawkes, eds). Chapman and Hall, UK. 263-285 pp. 
Benin S, M Smale, B Gebremedhin, J Pender and S Ehui. 2003. The economic determinants of cereal crop diversity on farms in the Ethiopian Highlands. Paper presented in $25^{\text {th }}$ International Conference of Agricultural Economists, 16-22 August 2003, Durban-South Africa.

Brennan JP and D Byerlee. 1991. The rate of crop variety replacement on-farms. Measures and empirical results for wheat. Plant Varieties and Seeds 4:99-106.

Brush SB, Taylor JE and M Bellon. 1992. Technology adoption and biological diversity in Andean potato agriculture. Journal of Development Economics 39:365-387.

Duvik DN. 1984. Genetic diversity in major farm crops on the farm and in reserve. Economic Botany 38(2):161178.

Gauchan D. 2000. Economics and diversity of rice-based production systems in Nepal's Central Tarai. In: Advances in agricultural research in Nepal (HK Manandhar, CL Shrestha, RK Shrestha and SM Pradhan, eds). Proceedings of the First-SAS Convention. Society of Agricultural Scientist, Kathmandu, Nepal. Pp. 49-57.

Gauchan D. 2004. Conserving crop genetic resources on-farm. The case of rice in Nepal. PhD Thesis. University of Birmingham, UK. 278 pp.

Greene WH. 1998. LIMDEP Version 7.0 Users manual. Revised edition. Econometric Software Inc. USA. 924pp.

Greene WH. 2000. Econometric analysis. Fourth Edition. Prentice Hall. USA.1004 pp.

Magurran AE. 1991. Ecological diversity and its measurement. Princeton University Press, Princeton, N.J.

Meng ECH, M Smale, M, Bellon and D Grimanelli. 1998. Definition and measurement of crop diversity for economic analysis. In: Farmers, gene banks and crop breeding: Economic analysis of diversity in wheat, maize and rice (M Smale, ed). Norwell, USA; Kulwer Academic Publishers, CIMMYT-Mexico.

Meng ECH. 1997. Land allocation decisions and in situ conservation of crop genetic resources: The case of wheat landraces in Turkey. Doctoral dissertation. University of California-Davis. $172 \mathrm{pp}$.

Singh I, L Squire and J Strauss (eds). 1986. Agricultural household models: Extensions, applications, and policy. The World Bank and Johns Hopkins University Press, Washington DC, and Baltimore.

Smale M, E Meng, JP Brennan and R Hu. 2003. Determinants of spatial diversity in modern wheat: examples from Australia and China. Agricultural Economics 28(1):13-26

Smale M, M.Bellon and A Aguirre. 2001. Maize diversity, variety attributes and farmers' choices in South-eastern Guanajuato, Mexico. Economic Development and Cultural Change 50(1):201-225.

Sthapit B, MP Upadhyay and A Subedi (eds). 2000. A scientific basis of in situ conservation of agro-biodiversity on-farm: Nepal's contribution to the global project. NP Working Paper No. 1/99. NARC/LIBIRD/IPGRI, Nepal.

Van Dusen E and JE Taylor. 2003. Missing markets and crop genetic resources: evidence from Mexico. University of California, Berkeley, USA.

Van Dusen E. 2000. In situ conservation of crop genetic resources in Mexican Milpa systems. PhD Thesis. University of California, Davis, USA. 135 pp.

Winkelmann R and KF Zimmerman. 1995. Recent developments in count data modelling: Theory and application. Journal of Economic Survey 9:1-24. 